\title{
SECAGEM DE PIMENTA-DO-REINO PRETA (Piper nigrum L.) EM SECADOR DE LEITO FIXO
}

\author{
D. A. S. ALVES ${ }^{1}$, H. PERAZZINI ${ }^{2}$, F. B. FREIRE ${ }^{3}$, J. T. FREIRE ${ }^{4 *}$ \\ ${ }^{1}$ UFSCar CCET/DEQ \\ ${ }^{2}$ UNIFEI / Instituto de Recursos Naturais \\ ${ }^{3,4}$ Universidade Federal de São Carlos / Departamento de Engenharia Química \\ e-mail: freire@ufscar.br
}

\begin{abstract}
RESUMO
A pimenta do reino preta é a mais importante especiaria comercializada mundialmente, sendo o Brasil um dos maiores produtores. Mesmo assim, poucos estudos para otimização do processo produtivo dessa commodity foram realizados. O objetivo desse trabalho foi estudar a secagem dos grãos de pimenta-do-reino preta. Foi realizada a caracterização físico-química do material com umidades variadas, medindo-se as dimensões lineares (diâmetro de Sauter, diâmetros mínimo, médio e máximo, e perímetro), da área superficial, volume, esfericidade, e ainda a massa específica aparente, real e bulk, e as porosidades dos grãos. Os experimentos de cinética de secagem foram realizados em camada fina, em um secador de convecção forçada com temperatura variando de 50 a $70^{\circ} \mathrm{C}$, e com velocidade do ar de 2,0 e 4,0 m/s. Com esses dados, fizeram-se ajustes das equações de Lewis, Page e Overhults, e do modelo Difusivo com hipóteses simplificadoras para a difusividade. Os resultados obtidos mostram que o modelo difusivo foi o mais adequado.
\end{abstract}

\section{INTRODUÇÃO}

A pimenta-do-reino é originária da Índia e, desde a década de 1930, quando foi introduzida no Brasil, por imigrantes japoneses, tem sido o suporte econômico de pequenos e grandes produtores da Região Amazônica (CHU, 2006). O Brasil é o segundo maior exportador mundial dessa commodity, tendo os estados do Pará, Espírito Santo, Bahia, Paraíba e Maranhão como os maiores produtores nacionais, respectivamente (IBGE, 2013). Dependendo do processamento, a pimenta-do-reino pode ser manufaturada nas colorações verde, branca e preta, sendo a última resultado da colheita do fruto totalmente desenvolvido e posteriormente seco (CHU, 2006). Dentre as etapas do processo produtivo, a secagem do material é fundamental para garantir a qualidade ao produto, diminuir a incidência de doenças e pragas, e auxiliar no processo de armazenamento e distribuição. (RAVINDRAN,2000)

A secagem de pimenta-do-reino em território brasileiro ocorre em sua maioria de duas maneiras distintas, utilizando secadores mecânicos ou secagem ao sol, sendo que em ambas as perdas são significativas. A escassez de trabalhos na literatura sobre a pimenta-doreino, e mais especificamente sobre a secagem dessa especiaria aumenta a motivação por essa pesquisa.

Uma das formas mais eficientes de se analisar o processo de secagem de um determinado produto baseia-se no desenvolvimento de modelos matemáticos para descrição do fenômeno físico, ou seja, no emprego da simulação (SINÍCIO, 1983). Diversos modelos de simulação do processo de secagem têm sido empregados no projeto de novos sistemas de secagem, e na otimização dos já existentes, ou ainda no 
controle do processo (KARATHANOS E BELESSIOTIS, 1999).

O objetivo desse trabalho foi caracterizar os grãos de pimenta-do-reino e analisar o ajuste dos modelos de Page, Lewis, Overhults e Difusivo aos dados experimentais de curvas de secagem de pimenta-do-reino, e analisar também, a influência da temperatura e velocidade do ar no processo de secagem dos grãos de Piper Nigrum L.

\section{MATERIAL E MÉTODOS}

\subsection{Material}

A pimenta-do-reino (Piper Nigrum L.) utilizada (Figura 1) foi fornecida pela empresa Sacconi Comércio Exportação e Beneficiamento de Produtos Agrícolas Ltda., situada ao norte do estado do Espírito Santo, na cidade de São Mateus.

Figura 1 - Pimenta-do-reino preta seca utilizada no trabalho

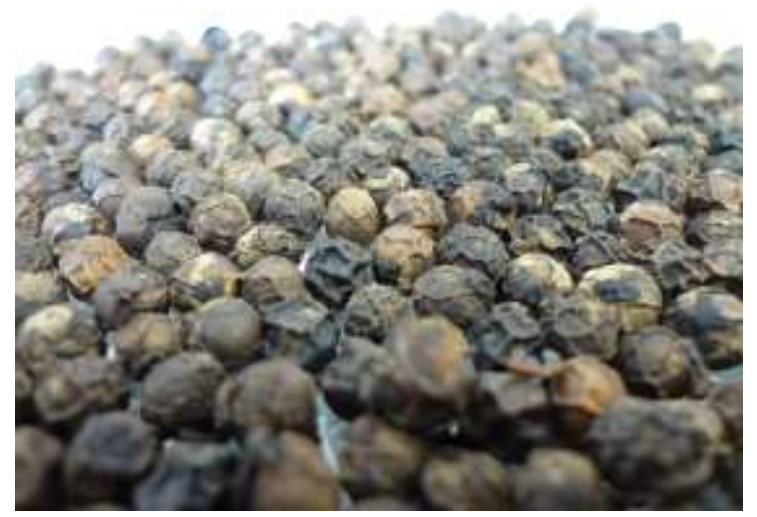

Fonte: Acervo pessoal (2014).

\subsection{Métodos}

\subsubsection{Peneiramento}

Para a análise granulométrica empregouse a técnica do peneiramento agitado utilizando o agitador da marca Retsch AS 200 control, a fim de se classificar uma massa conhecida de grãos utilizando peneiras com aberturas de diâmetro médio $\left(\mathrm{D}_{i}\right) 3,35 \mathrm{~mm}$; 4,76 $\mathrm{mm} ; 4 \mathrm{~mm}$ e $3,35 \mathrm{~mm}$ da marca Tyler.
Através da massa de sementes retidas em cada peneira calculou-se o diâmetro de Sauter $(\bar{D})$ de acordo com a Equação 1 (FUMAGALLI, 2007).

$$
\bar{D}=\frac{1}{\sum_{i=1}^{n} x_{i} / D_{i}}
$$

\subsubsection{Análise de Imagens}

As imagens dos grãos de pimenta-doreino foram obtidas com uma câmera digital Sony Cibershot DSC-WX50, com definição de 16,2 megapixels. Os grãos foram distribuídos sobre uma folha de papel milimetrado, distantes o suficiente para a análise. As imagens foram tiradas em triplicata em vários instantes do processo de secagem dos grãos estudados. Utilizou-se o software Image Pro Plus 6 para a análise das imagens, utilizando a distância de $1 \mathrm{~cm}$ como gabarito, para conversão de pixels em centímetros. As características do material determinadas pelo software foram o diâmetro médio (B), comprimento (L), largura (W) e espessura (T). Através dos dados obtidos, foi possível calcular o volume (V), área superficial (S), e esfericidade ( $\phi)$ (MOHSENIN, 1986), respectivamente pelas Equações 2,3 e 4 .

$$
V=\frac{\pi \cdot B^{2} \cdot L^{2}}{6(2 L-B)}
$$

$$
S=\frac{\pi \cdot B \cdot L^{2}}{2 L-B}
$$

$\phi=\frac{\sqrt[3]{W \cdot T \cdot L}}{L}$

\subsubsection{Densidade de Bulk}

A densidade de bulk $\left(\rho_{\mathrm{b}}\right)$, ou volumétrica, é dada pela relação entre a massa 
(m) e o volume do leito empacotado $\left(V_{b}\right)$. Foram realizados ensaios em triplicata com auxílio de uma proveta de $250 \mathrm{ml}$. A amostra de partículas foi empacotada no leito com auxílio de um funil para derramar as sementes no interior do recipiente (PEREIRA, 2010). Para melhorar a acomodação dos grãos, algumas batidas na base do leito proveta foram efetuadas (ZOTIN,1985). Através da razão entre massa de partículas e o volume da proveta foi possível determinar a densidade de bulk pela Equação 5.

$$
\rho_{b}=\frac{m}{V_{b}}
$$

Através desses valores é possível calcular a porosidade do leito $\left(\varepsilon_{b}\right)$, que é dada pela relação entre o volume de vazios entre as partículas e o volume total do leito e se relaciona com a densidade de bulk e massa específica aparente $\left(\rho_{a p}\right)$ pela Equação 6.

$$
\varepsilon_{b}=1-\frac{\rho_{b}}{\rho_{a p}}
$$

\subsubsection{Picnometria}

Para determinar a massa específica aparente $\left(\rho_{a p}\right)$, foi utilizada a técnica de picnometria líquida, utilizando tolueno, de acordo com a metodologia da Association of Official Analytical Chemist, AOAC (2000), sendo obtidos a massa $(m)$ e volume dos grãos $\left(V_{a p}\right)$, determinando em seguida a massa específica aparente da pimenta-do-reino com auxílio da Equação 7. Foram realizadas quatro réplicas em cada ensaio.

$$
\rho_{a p}=\frac{m}{V_{a p}}
$$

\subsubsection{Condutividade Térmica}

O procedimento para determinar a condutividade térmica do leito de partículas consistiu em realizar medidas de temperatura ao longo do tempo, durante o aquecimento do leito. Técnica essa conhecida como sonda linear em regime transiente, recomendada por Zotin (1985). Nela, foram obtidos dados da variação de temperatura ao longo do tempo. Para calcular a condutividade térmica, ajustouse os dados experimentais à Equação 8 (PEREIRA,2010).

$K_{e f}=\frac{q / 4 \cdot \pi}{d \Delta T / d \ln T}$

\subsubsection{Secagem em Camada Fina}

A pimenta-do-reino preencheu a célula de medida com diâmetro de $0,10 \mathrm{~m}$ e altura de $0,01 \mathrm{~m}$. O secador de convecção forçada foi ligado com uma célula idêntica acoplada, com o intuito de atingir o regime permanente (temperatura e vazão do ar constantes), sendo que, ao ser atingido, essa célula era substituída rapidamente pela célula contendo a amostra. O sistema permaneceu sob condições operacionais constantes de vazão e temperatura do ar de secagem. Neste trabalho serão apresentados apenas os dados de $50^{\circ} \mathrm{C}$, uma temperatura intermediária de $60^{\circ} \mathrm{C}$ e uma temperatura máxima de $70^{\circ} \mathrm{C}$. Para a velocidade do ar, testes iniciais indicaram que a velocidade do ar tinha pouca influência sobre a secagem, dessa maneira, foram escolhidos valores bem diferenciados de velocidade, sendo o valor mínimo de $2,0 \mathrm{~m} / \mathrm{s}$ e máximo de $4,0 \mathrm{~m} / \mathrm{s}$. A célula de secagem preenchida com a amostra foi pesada em intervalos de tempo pré-determinados em uma balança analítica da marca GEHAKA modelo BG400 com precisão de 0.001g. Após a pesagem, a célula era rapidamente acoplada ao secador, sendo esse procedimento realizado até que massa entre duas amostragens fosse praticamente constante. Aos dados experimentais obtidos, ajustou-se 
os modelos de Page, Lewis, Overhults e Difusivo (através do software Matlab 7). Foram utilizados parâmetros estatísticos para análise de adequação dos modelos aos dados experimentais. Utilizou-se o software para calcular os valores da difusividade efetiva $\left(D_{e f)}\right.$.

\section{RESULTADOS E DISCUSSÃO}

\subsection{Peneiramento}

Os dados obtidos no experimento de peneiramento agitado estão apresentados no gráfico da Figura 3.

Figura 3 - Fração mássica dos grãos retidos nas peneiras

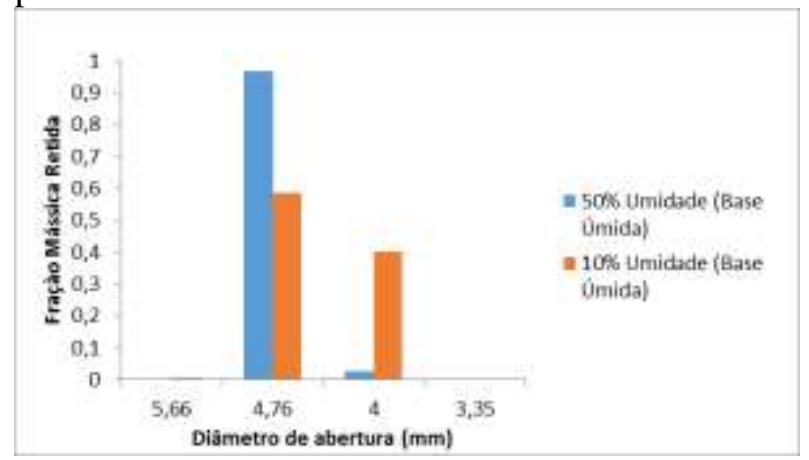

Fonte: Acervo pessoal (2015).

De posse de tais dados, foi possível obter os dados do diâmetro de Sauter para as umidades de $10 \%$ e $50 \%$ em base úmida, respectivamente $4,42 \mathrm{~mm}$ e $4,73 \mathrm{~mm}$.

\subsection{Dimensões Intrínsecas}

$\mathrm{Na}$ Tabela 1 estão apresentados os dados obtidos por análise de imagens das dimensões dos grãos de pimenta-do-reino ao chegarem ao Centro de Secagem do DEQ/UFSCar.
Tabela 1 - Dimensões intrínsecas dos grãos de pimenta-do-reino

\begin{tabular}{ccc}
\hline $\begin{array}{c}\text { Dimensões } \\
\text { Intrínsecas }\end{array}$ & Unidade & Amostra \\
\hline Umidade em base & $\mathrm{X}_{\mathrm{bu}}[\%]$ & $65,0 \%$ \\
úmida & & \\
Umidade em base & $\mathrm{X}_{\mathrm{bs}}$ & $2,06 \pm 0,01$ \\
seca & $\mathrm{L}[\mathrm{mm}]$ & $7,40 \pm 0,14$ \\
Comprimento & $\mathrm{W}[\mathrm{mm}]$ & $7,19 \pm 0,12$ \\
Largura & $\mathrm{T}[\mathrm{mm}]$ & $7,09 \pm 0,12$ \\
Espessura & $\mathrm{D}_{\min }[\mathrm{mm}]$ & $7,19 \pm 0,12$ \\
Diâmetro Mínimo & $\mathrm{D}_{\operatorname{máx}}[\mathrm{mm}]$ & $7,4 \pm 0,12$ \\
Diâmetro Máximo & $\mathrm{D}_{\mathrm{m}}[\mathrm{mm}]$ & $7,24 \pm 0,12$ \\
Diâmetro Médio & $\mathrm{P}\left[\mathrm{mm}^{2}\right]$ & $23,72 \pm 0,74$ \\
Perímetro & $\mathrm{A}_{\mathrm{p}}\left[\mathrm{mm}^{2}\right]$ & $44,86 \pm 2,24$ \\
Área Projetada & $\mathrm{S}\left[\mathrm{mm}^{2}\right]$ & $160,26 \pm 7,19$ \\
Área Superficial & $\mathrm{V}\left[\mathrm{mm}^{3}\right]$ & $190,59 \pm 9,44$ \\
Volume & $\varphi[-]$ & 0,97 \\
Esfericidade &
\end{tabular}

Fonte: Acervo pessoal (2015).

\subsection{Medidas de Densidade}

Após a realização dos experimentos de picnometria líquida em tolueno e testes em proveta, e posterior tratamento dos dados, obteve-se valores das densidades e porosidades do leito e da partícula, observados na Tabela 2.

Tabela 2 - Características físicas determinadas pelas medidas de densidade da partícula e do leito

\begin{tabular}{ccc}
\hline Parâmetro & $\begin{array}{c}10 \% \text { Umidade } \\
\text { (Base Úmida) }\end{array}$ & $\begin{array}{c}55 \% \text { Umidade } \\
\text { (Base Úmida) }\end{array}$ \\
\hline$\rho_{\mathrm{ap}}\left(\mathrm{g} / \mathrm{cm}^{3}\right)$ & 0,95 & 1,05 \\
$\rho_{\mathrm{b}}\left(\mathrm{g} / \mathrm{cm}^{3}\right)$ & 0,62 & 0,70 \\
$\varepsilon_{\mathrm{b}}$ & 0,35 & 0,34 \\
\hline
\end{tabular}

Fonte: Acervo pessoal (2015).

Para a variação de umidade de $10 \%$ a 55\% (Base Úmida), a densidade aparente e de bulk variaram pouco. O mesmo observou-se para a porosidade do leito.

\subsection{Condutividade Térmica}

Na Tabela 3 estão apresentados os dados obtidos de $\mathrm{K}_{\mathrm{ef}}$ dos grãos de pimenta-do- 
reino na umidade inicial (55\% b.u.) e para umidade de $10 \%$ (b.u.).

Tabela 3 - $\mathrm{K}_{\mathrm{ef}}$ para diferentes umidades

\begin{tabular}{cc}
\hline Umidade (b.u.) & $K_{e f}(\mathrm{~W} / \mathrm{m} . \mathrm{K})$ \\
\hline $10 \%$ & $0,0242 \pm 0,0067$ \\
$55 \%$ & $0,0337 \pm 0,0067$ \\
\hline
\end{tabular}

Fonte: Acervo pessoal (2015).

De acordo com os dados da Tabela 2, no intervalo de 10 a 55\% da umidade (b.u.), o $\mathrm{K}_{\text {ef }}$ do leito dos grãos de pimenta do reino variou de 0,0242 a $0,0337 \mathrm{~W} / \mathrm{m} . \mathrm{K}$, um crescimento de $39,3 \%$.

\subsection{Secagem em Camada Fina}

Na Figura 4 estão apresentadas as curvas experimentais de secagem da pimenta-do-reino preta, na faixa de temperatura de 50 a $70^{\circ} \mathrm{C}$. Pode-se observar, pela Figura 4, que nos primeiros 100 minutos de experimento, a temperatura não exerce influência significativa na secagem. Isso se deve ao fato da água retirada nestes instantes ser fracamente ligada ao substrato. Dessa forma, pequenas quantidades de energia são suficientes para a retirada da água do material. A partir de tal tempo, pode-se claramente observar que o tempo de secagem é menor para a temperatura de $70^{\circ} \mathrm{C}$, intermediário para $60^{\circ} \mathrm{C}$ e maior para $50^{\circ} \mathrm{C}$, ou seja, com o aumento da temperatura ocorreu diminuição do tempo de secagem, isto porque, com o aumento de $\mathrm{T}$, foi fornecida mais energia térmica ao processo. A cinética de secagem da pimenta-do-reino preta apresenta as mesmas características da maioria dos grãos agrícolas (ALMEIDA et al., 2009), ou seja, existe uma clara dependência da velocidade da secagem com a temperatura do ar. Segundo Peske et al. (2003), a utilização de temperaturas elevadas permite uma secagem mais rápida, porém, pode provocar diferença de teor de água entre a periferia e o centro da semente, gerando um gradiente de pressão possível de causar danificação mecânica.

Figura 4 - Umidade adimensional em função do tempo para temperaturas de 50,60 e $70^{\circ} \mathrm{C}$.

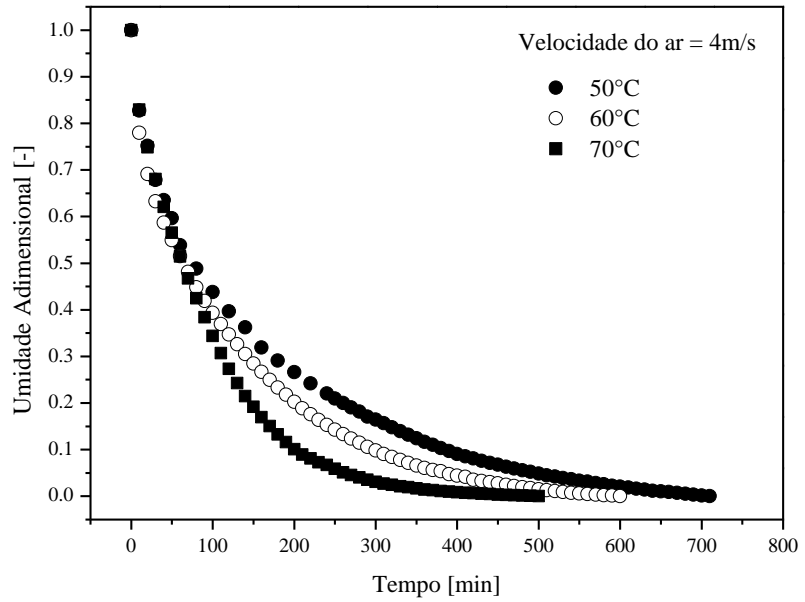

Fonte: Acervo pessoal (2015).

Figura 5 - Variação da Umidade Adimensional durante a secagem de pimentado-reino preta para temperatura de $70^{\circ} \mathrm{C}$, a velocidade de $2 \mathrm{~m} / \mathrm{s}$ e $4 \mathrm{~m} / \mathrm{s}$

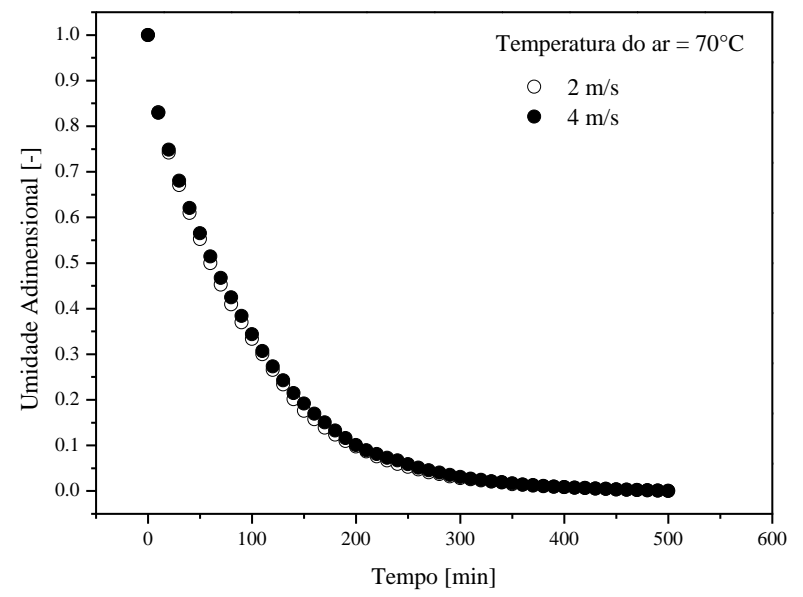

Fonte: Acervo pessoal (2015).

A Figura 5 apresenta os dados de umidade adimensional (UA) em função do tempo de secagem, numa mesma temperatura $\left(70^{\circ} \mathrm{C}\right)$, para velocidade do ar de $2 \mathrm{~m} / \mathrm{s}$ e $4 \mathrm{~m} / \mathrm{s}$. De forma visual, observa-se que a velocidade do ar não exerce influência significativa no processo de secagem. Este efeito sugere que a resistência externa não influencia nas 
condições de operações utilizadas e que o controle da secagem da pimenta-do-reino depende da difusão interna desse grão.

\subsection{Ajuste de Modelos}

Aos dados experimentais de secagem foram ajustados os modelos de Page, Lewis e Overhults e o Difusivo (Tabela 4), podendo ser visualizados na Figura 10.

Tabela 4 - Equações dos modelos de Lewis, Page, Overhults e modelo Difusivo

\begin{tabular}{cc}
\hline Modelo & Equação \\
\hline Lewis & $\mathrm{UA}=\exp (-K t)$ \\
Page & $\mathrm{UA}=\exp \left(-K t^{n}\right)$ \\
Overhults & $\mathrm{UA}=\exp \left[\left(-K t^{n}\right)\right]$ \\
& $\mathrm{UA}=\frac{8}{\pi^{2}} \sum_{n=0}^{\infty} \frac{1}{(2 n+1)^{2}} \exp \left(-\frac{(2 n+1)^{2} \pi^{2} D_{g f} t}{4 L^{2}}\right)$
\end{tabular}

Em que: UA - umidade adimensional, adimensional; $\mathrm{t}$ - tempo, minutos; $\mathrm{K}$ - coeficiente de secagem; $\mathrm{n}$ constante dos modelos; Def - difusividade efetiva, (m2/m); L - espessura, metros.

Fonte: PERAZZINI (2014).

Pode-se verificar na Tabela 5 os resultados obtidos para as equações analisadas, sendo $\mathrm{R}^{2}$ o coeficiente de correlação e SE o erro médio estimado.

Tabela 5 - Parâmetros estatísticos para o ajuste dos modelos

\begin{tabular}{ccc}
\hline Modelo & $\mathrm{R}^{2}$ & $\mathrm{SE}$ \\
\hline Lewis & 0,9967 & 1,0816000 \\
Page & 0,9986 & 0,0073500 \\
Overhults & 0,9971 & 0,0069500 \\
Difusivo & 0,9905 & 0,0000003 \\
\hline
\end{tabular}

Fonte: Acervo pessoal (2015).

Todos os modelos apresentaram ajustes satisfatórios à secagem de pimenta-do-reino, que forneceram resultados para os coeficientes de determinação superiores a 0,99. Madamba et al. (1996) ressaltam que o coeficiente de determinação $\left(\mathrm{R}^{2}\right)$, isolado, não é capaz de determinar satisfatoriamente o melhor modelo, sendo necessário analisar outros coeficientes. Sendo assim, o modelo Difusivo obteve, além do valor de $\mathrm{R}^{2}$ próximo da unidade, o menor valor do erro médio estimado, sendo o mais adequado no ajuste aos dados experimentais.

Figura 6 - Variação da Umidade Adimensional durante a secagem de pimentado-reino preta e ajuste das equações de Lewis, Page e Overhults

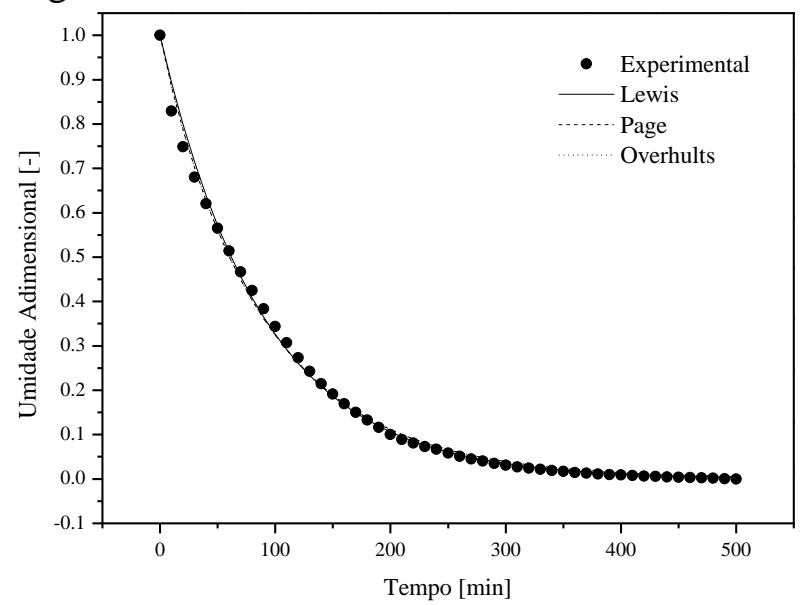

Fonte: Acervo pessoal (2015).

Figura 7 - Variação da Umidade Adimensional durante a secagem de pimentado-reino preta e ajuste do Modelo Difusivo

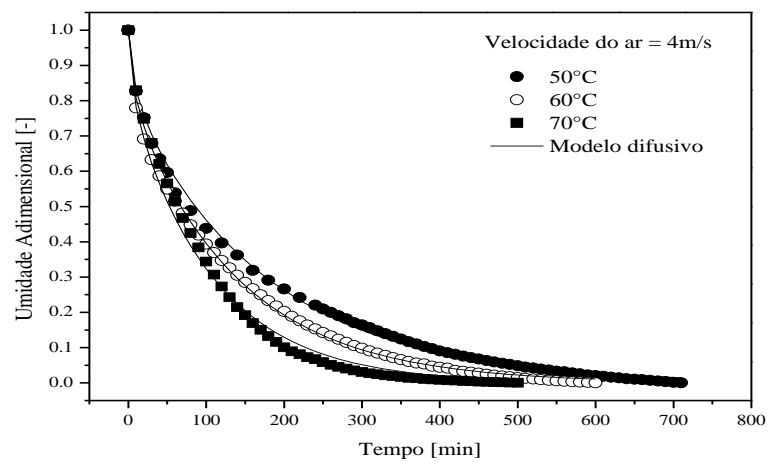

Fonte: Acervo pessoal (2015).

$\mathrm{Na}$ Figura 7, o modelo difusivo foi ajustado aos pontos experimentais de secagem. Pode-se observar também visualmente que o ajuste do modelo foi satisfatório para as temperaturas de 50, 60 e $70^{\circ} \mathrm{C}$. Como 
esperado, os valores do coeficiente de difusividade efetiva determinados pelo modelo difusivo aumentaram com o aumento da temperatura, evidenciando a diminuição da resistência interna, facilitando a difusão de umidade dentro do grão. Tais valores são verificados na Tabela 6.

Tabela 6 - Valores da Difusividade Efetiva para a faixa de temperatura de secagem

\begin{tabular}{cc}
\hline $\mathrm{T}\left({ }^{\circ} \mathrm{C}\right)$ & $\mathrm{D}_{\text {ef }}\left(\mathrm{m}^{2} / \mathrm{min}\right)$ \\
\hline 50 & $5,71 \times 10^{-8}$ \\
60 & $7,28 \times 10^{-8}$ \\
70 & $9,30 \times 10^{-8}$ \\
\hline
\end{tabular}

Fonte: Acervo pessoal (2015).

\subsection{Encolhimento}

Para avaliar o efeito da secagem na mudança de forma e encolhimento do fruto, bem como dos seus subsistemas, foi realizada a tomada de imagens durante todo o processo de secagem para cada parte estudada. As imagens foram analisadas com o auxílio do software Image Pro Plus ${ }^{\circledR}$, para constatar o efeito da secagem sobre o encolhimento dos grãos de pimenta-do-reino preta (Figura 8).

Figura 8 - Imagens dos grãos de pimenta-doreino durante o processo de secagem

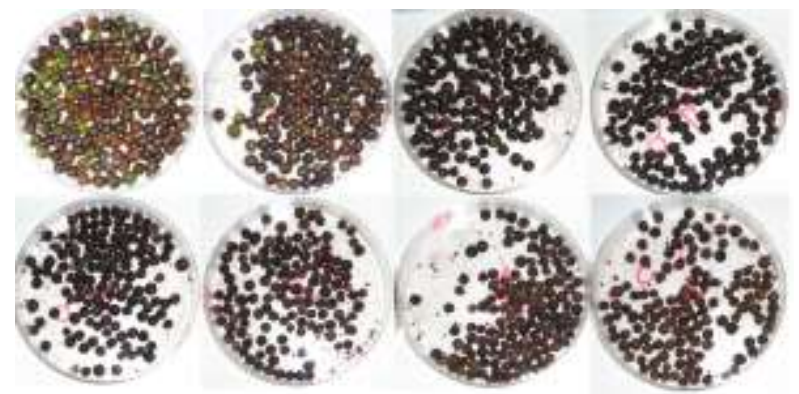

Fonte: Acervo pessoal (2015).

Após a análise de imagens pelo software, foram utilizadas as Equações 2, 3, 4 e 5 para calcular os valores do diâmetro médio da partícula, volume, área superficial, perímetro e esfericidade durante o processo de secagem. Nas Figuras de 9 a 15 estão apresentados os resultados adimensionais.

Figura 9 - Adimensional de diâmetro médio em função do tempo de secagem $\left(\mathrm{T}=50^{\circ} \mathrm{C}\right.$, $\mathrm{v}_{\mathrm{ar}}=2,0 \mathrm{~m} / \mathrm{s}$ ).

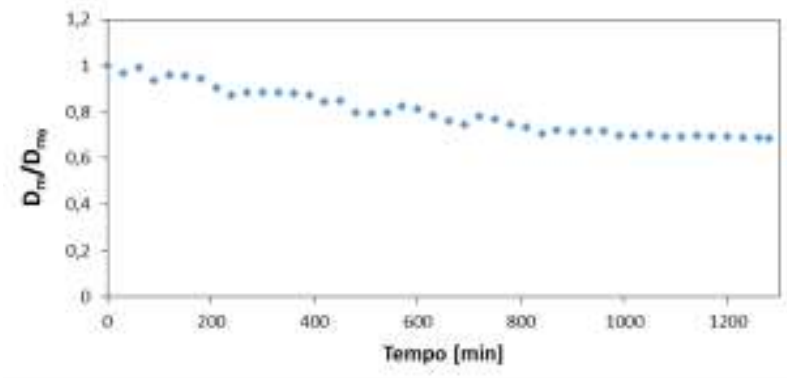

Fonte: Acervo pessoal (2015).

Figura 10 - Adimensional de diâmetro mínimo em função do tempo de secagem $\left(\mathrm{T}=50^{\circ} \mathrm{C}, \mathrm{v}_{\mathrm{ar}}=2,0 \mathrm{~m} / \mathrm{s}\right)$.

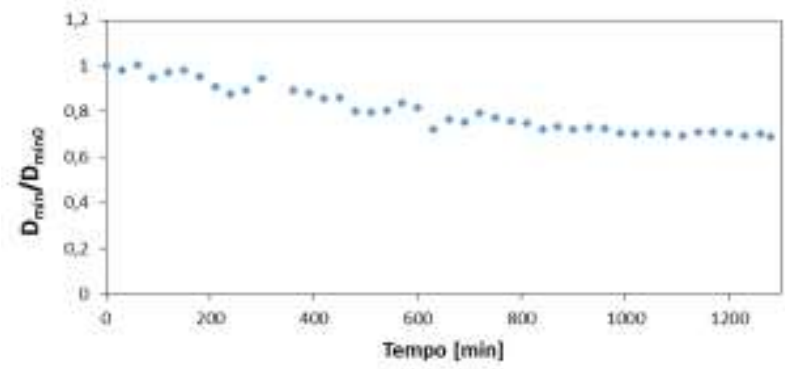

Fonte: Acervo pessoal (2015).

Figura 11 - Adimensional de diâmetro máximo em função do tempo de secagem $\left(\mathrm{T}=50^{\circ} \mathrm{C}, \mathrm{v}_{\mathrm{ar}}=2,0 \mathrm{~m} / \mathrm{s}\right)$.

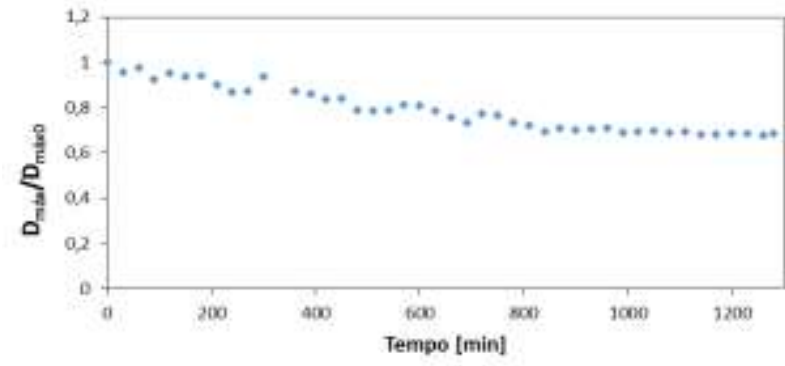

Fonte: Acervo pessoal (2015). 
Figura 12 - Adimensional de perímetro em função do tempo de secagem $\left(\mathrm{T}=50^{\circ} \mathrm{C}\right.$, $\mathrm{v}_{\mathrm{ar}}=2,0 \mathrm{~m} / \mathrm{s}$ ).

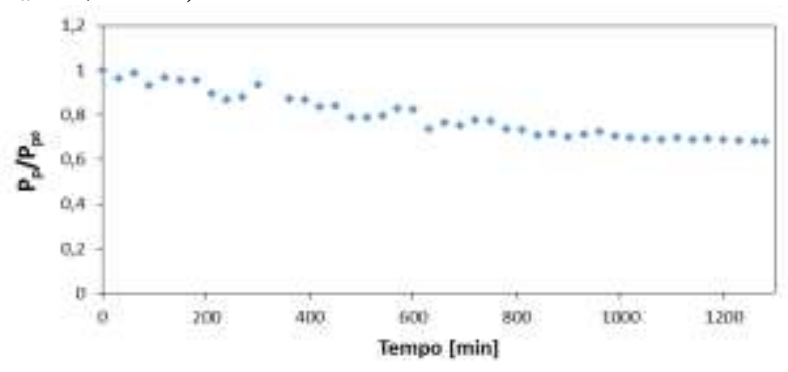

Fonte: Acervo pessoal (2015).

Figura 13 - Adimensional de área superficial em função do tempo de secagem $\left(\mathrm{T}=50^{\circ} \mathrm{C}\right.$, $\mathrm{v}_{\mathrm{ar}}=2,0 \mathrm{~m} / \mathrm{s}$ )

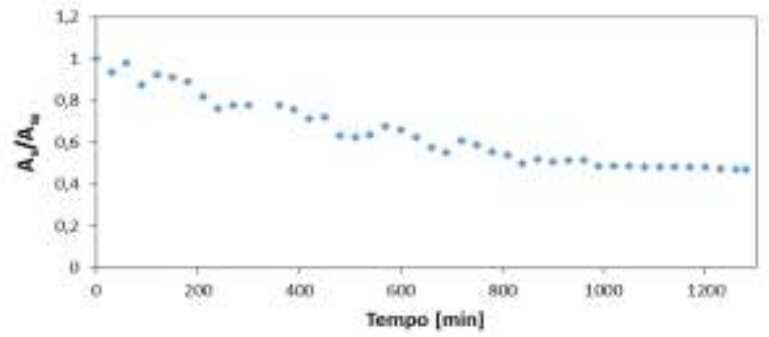

Fonte: Acervo pessoal (2015).

Figura 14 - Adimensional de volume em função do tempo de secagem $\left(\mathrm{T}=50^{\circ} \mathrm{C}\right.$, $\mathrm{v}_{\mathrm{ar}}=2,0 \mathrm{~m} / \mathrm{s}$ ).

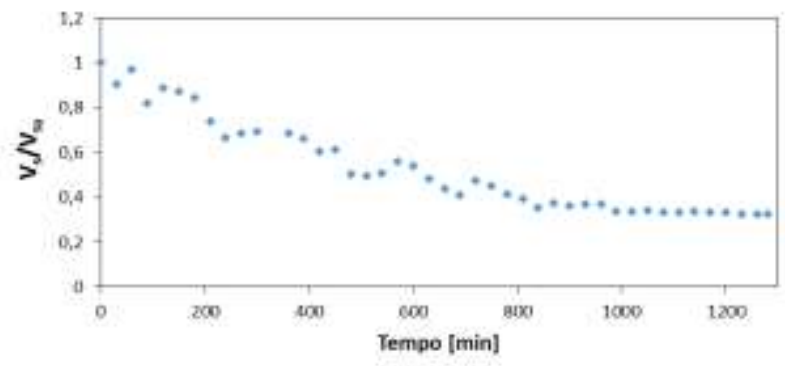

Fonte: Acervo pessoal (2015).
Figura 15 - Esfericidade em função do tempo $\left(\mathrm{T}=50^{\circ} \mathrm{C}, \mathrm{v}_{\mathrm{ar}}=2,0 \mathrm{~m} / \mathrm{s}\right)$.

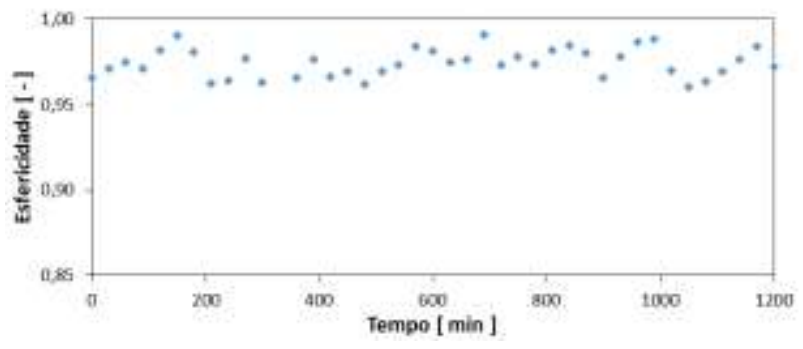

Fonte: Acervo pessoal (2015).

Nas figuras de 13 a 18 pode-se perceber o acentuado encolhimento em todas as características estudadas.

Em todas as características descritas, o comportamento foi praticamente linear até aproximadamente 850 minutos, a partir desse instante a variação não ultrapassou $3 \%$, pelo fato dos grãos estarem enrijecidos pelo processo de secagem, reduzindo significativamente o encolhimento.

$\mathrm{Na}$ Figura 19 observa-se que a variação de esfericidade permaneceu entre 0,95 e 1,00 durante todo o processo de secagem. A proximidade ao valor unitário representa a manutenção da geometria esférica durante o experimento. Dessa forma, pode-se inferir que não há deformação do produto. Além disso, para futuras modelagens, pode-se realizar o equacionamento dos fenômenos de transferência envolvidos em geometria esférica.

\section{CONCLUSÃO}

Nos ensaios de caracterização, constatou-se que o diâmetro médio, área superficial, perímetro e volume diminuem durante a secagem da pimenta-do-reino de forma linear, com encolhimento significativo do grão. Constatou-se também que a esfericidade não se altera com a variação do teor de umidade, mantendo a geometria esférica do grão. 
Com base nos resultados obtidos, observa-se que nos 100 primeiros minutos a secagem não foi significativamente influenciada pela temperatura. A partir desse instante, a influência da temperatura foi muito significativa e a velocidade do ar de secagem não obteve influência relevante. Conclui-se assim que o mecanismo que controla a secagem é a difusão interna.

Como esperado, os valores da difusividade efetiva obtidos aumentaram com o aumento da temperatura do ar de secagem de $5,71 \times 10^{-8} \mathrm{~m}^{2} / \mathrm{min}$ a $50^{\circ} \mathrm{C}$ para $9,30 \times 10^{-8}$ $\mathrm{m}^{2} / \mathrm{min}$ a $70^{\circ} \mathrm{C}$.

Através de análise estatística, todos os modelos ajustados obtiveram ajustes significativos na cinética de secagem. Dentre eles, o modelo Difusivo forneceu melhor ajuste aos dados experimentais.

O encolhimento foi observado em todas as condições de processo experimentais adotadas, com comportamento próximo ao linear até o enrijecimento da superfície do grão. As oscilações observadas ocorridas durante o encolhimento podem ser associadas à formação de nervuras na superfície dos grãos.

\section{REFERÊNCIAS}

ALMEIDA, D. P.; RESENDE, O.; COSTA, L. M.; MENDES, U. C.; SALES, J. F. Cinética de secagem do feijão adzuki (Vigna angularis). Global Science and Technology, v.2, p.72-83. 2009.

AOAC. Official Methods of Analysis of AOAC Intl, $17^{\text {th }}$ ed. Arlington, VA, USA: Association of oficial Analutical Communities. 2000.

CHU, E.Y., et al. A cultura da pimenta do reino. Brasília: EMBRAPA: 2.ed., 2006.
EMBRAPA. Manual segurança e qualidade para a cultura da pimenta-do-reino, EMBRAPA/SEDE, Brasília, 2004.

FUMAGALLI, F. Estudo da secagem das sementes de Brachiara brizantha. 2007. 149 f. Tese (Doutorado em Engenharia Química) - UFSCar, São Carlos, 2007.

IBGE. Instituto Brasileiro de Geografia e Estatística. Levantamento Sistemático da Produção Agrícola: Pesquisa Mensal de Previsão e Acompanhamento das Safras Agrícolas no Ano Civil. Rio de Janeiro: IBGE, v.26 n.1 p.1-83. Janeiro. 2013.

KARATHANOS, V.T.; BELESSIOTIS, V.G. Application of a thin-layer equation to data of fresh and semi-dried fruits. Journal of Agricultural Engineering Research, v. 74, p.355-361, 1999.

MADAMBA, P. S.; DRISCOLL, R. H.; BUCKLE, K. A. The thin layer drying characteristic of garlic slices. Jornal of Food Engineering, v.29, p.75-97, 1996.

MOHSENIN, N. N. Physical properties of plant and animal materials. New York: Gordon and Breach Publishers. 841 p., 1986.

PERAZZINI, H. Secagem de sólidos porosos granulares. 2014. Tese (Doutorado em Engenharia Química) - Departamento de Engenharia Química, Universidade Federal de São Carlos, São Carlos, SP, 2014.

PEREIRA, A.V. Caracterização e secagem de sementes de painço (Setaria italica L.) 2010. 92 f. Dissertação (Mestrado em Engenharia Química) - São Carlos, UFSCar, 2010.

PESKE, S. T.; VILLELA, F. Secagem de sementes. In: PESKE, S. T.; ROSENTHAL, M.; ROTA, G. R. M. Sementes: 
Fundamentos científicos e tecnológicos.

Pelotas: Editora e Gráfica Universitária (UFPel). p.283-322. 2003.

RAVINDRAN, P. N.; et al. Indian J. Arecanut Spices and Medicinal Plants. v. 2, p. 71-78, 2000.

SINÍCIO, R. Simulação de secagem de milho em camadas espessas a baixas temperaturas. 1983. 64 f. Dissertação (Mestrado em Engenharia Agrícola) - UFV, Viçosa, 1983.

ZOTIN, F.M.Z. O efeito de parede em colunas de recheio. 1985. 85 f. Dissertação (Mestrado em Engenharia Química) - São Carlos, UFSCar, 1985.

\section{AGRADECIMENTOS}

Agradeço a empresa Comercial Sacconi, por fornecer o material utilizado nessa pesquisa. 